\title{
Can RMB Exchange Rate Expectations Explain the Fluctuations of China's Housing Prices?
}

\author{
Chunni Wang ${ }^{1}$
}

\begin{abstract}
Unlike existing literature that has focused on the relationship between exchange rate and housing price, this paper studies the housing price fluctuations from the perspective of RMB exchange rate expectation to resolve the dilemma "guarantee housing price or exchange rate" after the sub-prime mortgage crisis. This paper shows that housing prices responded negatively to RMB appreciation expectation from 1999 to 2008, and positively from 2009 to 2019. After 2009, exchange rate expectation is the Granger causality of housing prices. After introducing the U.S. Economic Policy Uncertainty (EPU) released by Baker et al.(2016), the explanatory power of exchange rate expectations to housing price fluctuations declines but it's still significant. When EPU increased, housing prices responded negatively after a brief positive response. Besides exchange rate expectation, several unobservable factors with rich economic implications can explain the fluctuations of housing prices in China in the interval of 2006M01-2018M12. The empirical results show that the degree of Chinese government reversal intervention, interest rate spread between China and the U.S., and EPU can explain the exchange rate expectation. The government can control the degree of reversal intervention to affect the exchange rate expectation and realize the housing price control indirectly.
\end{abstract}

JEL classification numbers: E44, R31, G18

Keywords: RMB exchange rate expectations, China's housing price fluctuations, FAVAR model, Degree of reversal intervention.

${ }^{1}$ PBC School of Finance, Tsinghua University.

Article Info: Received: May 5, 2020. Revised: May 19, 2020.

Published online: July 1, 2020. 


\section{Introduction}

In 2008, the U.S. sub-prime mortgage crisis triggered the global financial crisis. Under the influence of the ultra-conventional monetary policies of the United States and Europe, the foreign exchange reserves of the People's Bank of China (PBOC, the central bank of China), accelerated and rose because of the surge of foreign capital based on asset security, relative return, and RMB unilateral appreciation expectations despite the foreign exchange control policy enacted by the Chinese government. In November 2008, the Chinese government launched the "Four Trillion" stimulus policy, which was driven by investment demand for railway, highway, and infrastructure projects, to minimize the effect of the crisis. Local governments of China encouraged real estate investment because of the financial contributions of the land. In the context of abundant domestic and foreign capital, banks increased development loans to real estate companies and mortgage loans to residents, which resulted in an increase in housing prices in China. The soaring housing prices and unilateral appreciation pressure caused the gradual emergence of its negative effects. Local governments implemented policies, including purchase restrictions, increased down payment ratio to curb houses prices, and prevent the domestic real estate market bubble from bursting, which might lead to a financial and economic crisis.

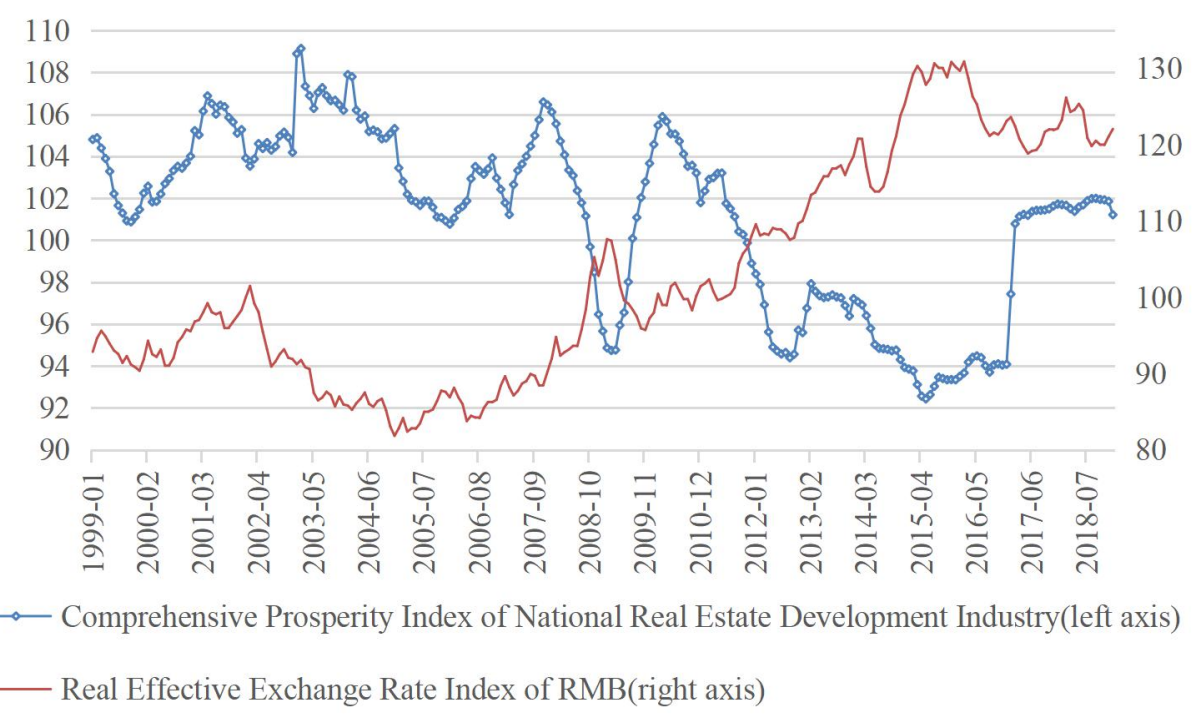

Figure 1: RMB real effective exchange rate and China housing climate degree Note. The data are from Bank for International Settlements (BIS) and the National Bureau of Statistics of China.

The 2015 Bloomberg U.S. Business Barometer index showed signs of recovery in the U.S. economy, while China's economy has experienced overcapacity and weak growth, and the size of its foreign exchange reserves began to decline 
because of the withdrawal of funds. On August 11, 2015, China carried out an exchange rate policy reform. By expanding the flexibility of bilateral exchange rate fluctuations, PBOC hoped to mend RMB unilateral appreciation expectations, increase speculation cost, and reduce the economic disorder caused by fluctuations in the foreign exchange market. As foreign exchange reserves continued to decline and affected the liquidity of domestic capital markets, PBOC replenished the domestic liquidity in a timely manner by using the medium-term lending facility, standing lending facility, and other structural policy tools. The growth of domestic housing prices slowed down under the influence of purchase restrictions and the increased down payment ratio policy. In fact, housing prices in many second-, third-, fourth-tier cities dropped dramatically. Figure 1 shows that the currency depreciation trend and domestic housing prices depression occurred at the same time after the exchange rate policy reform in 2015. "Guarantee housing price or exchange rate" became a hot issue for the Chinese government.

"Guarantee housing price or exchange rate" involves two types of asset price decisions and is a dilemma on the surface. On the one hand, if the Chinese government chooses to protect the RMB exchange rate, PBOC needs to raise interest rates but housing prices will decline due to increased financing costs. If it chooses to protect housing prices, PBOC needs to reduce the down payment ratio an unite with local governments or decrease interest rates, which might lead to the further depreciation of the RMB exchange rate, especially in the light of the U.S. and Europe hiking interest rate rumors. This paper holds that studies on the housing price fluctuations from the perspective of exchange rate expectation can help the Chinese government resolve its dilemma. Many factors determine the level and fluctuation of housing prices. This paper explores the explanatory power of exchange rate expectations to housing price fluctuations by using VAR and its extended model, the FAVAR model, both of which can better solve endogenous problems. Considering the U.S. economy's spillover effect on China's economy, this paper includes the news-based U.S. Economic Policy Uncertainty Index, the Effective Federal Funds Rate, Wu-Xia Shadow Rate ${ }^{1}$, the Industrial Production Index, CPI, and the Unemployment Rate into the FAVAR model.

The rest of the paper proceeds as follows. The second section reviews existing literature and proposes empirical hypotheses. The third provides a basic analysis of the VAR model, which investigates the interaction between the RMB exchange rate expectations and the housing price. The fourth section represents the results of the FAVAR model and OLS empirical analysis. The paper explores the effects of unobservable factors on housing prices in addition of the effects of the exchange rate expectations and searches for variables that can explain exchange rate expectations by including more variables. The last section concludes the entire paper.

\footnotetext{
${ }^{1}$ The Wu-Xia Shadow Rate was obtained from https://sites.google.com/site/jingcynthiawu/home/wu-xia-shadow-rates.
} 


\section{Literature review and empirical hypotheses}

Few studies focus on the relationship between housing prices and exchange rate expectations. This section expands on the literature range to exchange rate in addition to exchange rate expectations. Previous literature can be divided into three categories: qualitative, theoretical, and empirical views. Early literature used the qualitative method due to the limitations in data acquisition and method promotion. Gao et al. (2006) hold that exchange rate adjustment affects domestic housing prices through various effects including liquidity, expected, wealth, spillover, and credit expansion/contraction effects. Local currency appreciation will lead to higher domestic asset prices and lower foreign asset prices. Wang (2007) believes that the long-term undervaluation of the exchange rate has led to rapid urbanization and persistent current account surplus, and that the expected appreciation to attract hot money inflows and money supply through credit channels accelerated the promotion of real estate prices. Rising housing prices are the stress release points chosen by the market itself for high economic growth under exchange rate control.

The second strand of literature focuses on theoretical studies, which cover the local equilibrium and the general equilibrium models. Zhu et al. (2011) integrate the real estate and the foreign exchange markets and view foreign investors who purchase real estate and exchange currency as an analysis bridge. They find that the rise in housing prices and the appreciation of the exchange rate are driven by each other. Kuang (2013) assumes that foreign investment participates in the purchase and development of the real estate and the exchange rate variable is embedded in the local equilibrium stock model that can derive the relationship. Du et al. (2007) choose present value and transnational non-arbitrage perspective to construct the quantitative relationship between housing prices and exchange rate and believes that small fluctuations of the exchange rate will cause housing prices to change considerably through the land duration leverage effect. From an indirect intervention perspective, Meng (2014) assumes the exchange rate and housing prices as part of central bank policy targets, and both are related to the interest rate. If the interest adjustment follows a smoothing mechanism, the deriving formula shows that exchange rate appreciation raises housing prices. Zhu et al. (2010) incorporate the exchange rate, its expectation, and asset prices into the IS-LM-BP model and conclude that the exchange rate expectation effect on asset prices is more indirect. Tan et al. (2013) introduce exchange rate expectations into the central bank money supply function and embeds risk asset prices into investment function and credit capital availability ratio function. After building a joint market equilibrium model that includes the money, credit, asset, and commodity markets, they show that hot money can flow into the housing market and raise property prices. The money supply is also found to drive up property prices if the central bank has not adequately hedged. The DSGE model is a typical representation of the general equilibrium model. According to their NOEM-DSGE Model, Dong et al. (2017) find that housing prices and exchange rates change in different directions under different shocks. 
Foreign literature has focused on the relationship between stock price and exchange rate, and empirical research literature on housing price and exchange rate comes mainly from domestic studies. The conclusions usually include no obvious relationship, negative correlation, positive correlation, and conditional correlation . The main differences are the selection of agent variables, other explanatory variables, sample interval, frequency, and models. Some empirical studies focus on long-term relationships, short-term fluctuations, horizontal relationships, or variance spillover. Existing literature usually covers the period before or just after the sub-prime crisis and lacks longer period samples. Base on the VAR model, Zhu et al. (2010) find that housing prices rise under the effect of exchange rate depreciation but that the increase is decreasing. Housing prices are also found to respond negatively to exchange rate depreciation expectations in the first three periods and positive response after. Using the EGARCH and VAR model, Deng (2010) finds that housing prices and RMB appreciation are positive feedback for each other and that expanding the exchange rate volatility range will help regulate high housing prices. Through the MSVAR model, Zhu et al. (2011) hold that in some states, real exchange rate appreciation might lead a rise in real housing prices. According to the VAR-MGARCH -BEKK model, Liao et al. (2012) conclude that exchange rate elasticity reduces the correlation between the exchange rate and asset price. Tan et al. (2013) believe that appreciation expectations trigger hot money inflows, but the capital flow effect on housing prices is not significant . They further find that after adding M2 to the VAR model, the liquidity effect on housing prices is significant. The co-integration test shows the RMB appreciation expectation affects the long-term trend part of housing prices through wealth effect channels. Employing simultaneous equations and the 3SLS method, Kuang (2013) studies 35 cities of China panel data and determines that the exchange rate has no significant effect on housing prices. Using the VEC model, Meng (2014) finds that the increase in nominal effective exchange rate has a negative long-term effect on housing prices, while in the short-term, the effect is positive and then negative before recovery. Tan et al. (2015) construct the SVAR model and conclude that housing prices fall when the RMB exchange rate depreciates. Gai (2017 ) holds that the relationship of the RMB exchange rate and housing prices is insignificant because of capital control, purchase restriction policy, and unilateral changes in exchange rate. Zhong (2015) considers regional development imbalances and considers the FDI to be the intermediate variable to explain the relationship. The effects of the exchange rate on housing prices is regionally different, and tightening capital inflow controls is helpful to impair the influence.

Based on the findings of previous studies, this paper proposes four hypotheses.

Hypothesis I: The change in $R M B$ exchange rate expectation can explain the change in China's housing prices.

Hypothesis II: The unobservable factor representing medium- and longterm interest rates can explain the change in China's housing prices.

Hypothesis III: The unobservable factor representing the production and sale of durablegoodsandmoneysupplycan explain thechange ofChina's housing prices. 
Hypothesis IV: Previous exchange rate expectations, U.S. and China interest spread, $E P U$ and degree of reversal intervention of $P B O C$ can explain exchange rate expectations.

\section{Main Results of the VAR Model}

\subsection{Research designs}

This paper proposes the following regressions to examine the first hypothesis that the change in RMB exchange rate expectations can explain the change of China's housing prices:

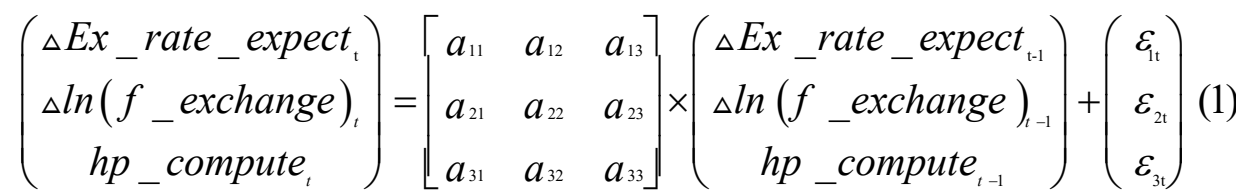

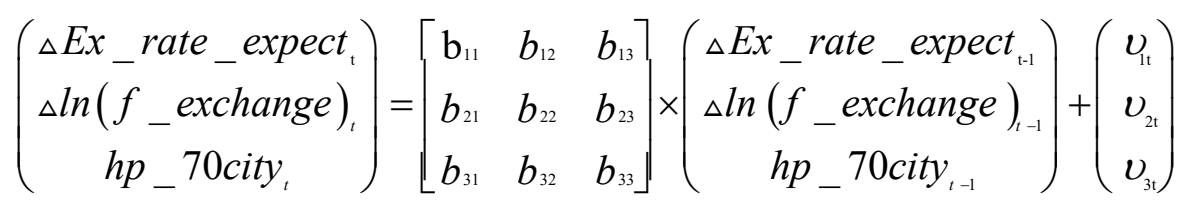

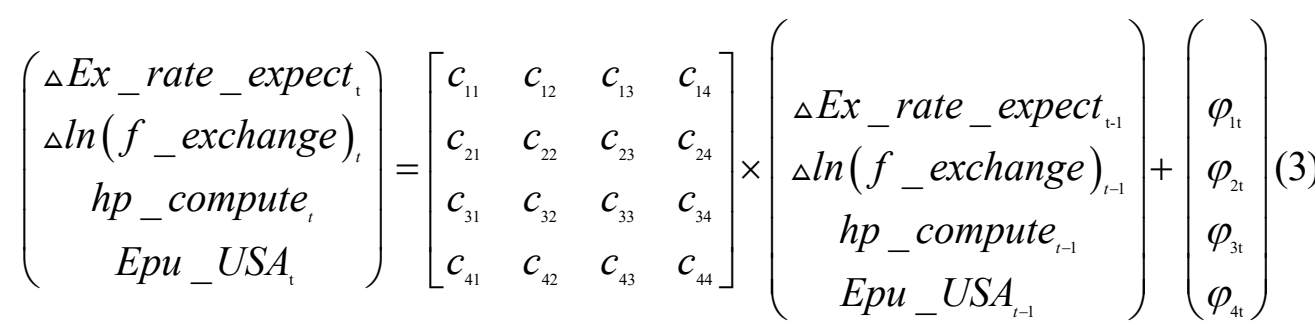

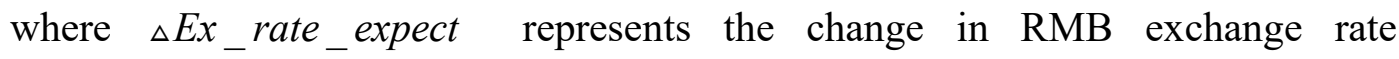
expectation, $\Delta \ln \left(f_{-}\right.$exchange $)$represents the growth rate of foreign exchange of PBOC, $h p$ _compute represents the degree of deviation from the steady-state of the national average housing price in China, $h p_{-} 70$ city represents the degree of deviation from the steady-state of a new residential housing price of 70 large and medium-sized cities in China, and Epu_USA represents the U.S. news-based economic policy uncertainty index from Baker et al. (2016). When impulse definition is correlated with Cholesky order, the order of variables above in each VAR model does not change. 


\subsection{Variables selection}

This paper uses time-series data at the macro level to examine those hypotheses and convert monthly or daily data into quarterly data to iron outliers. This paper studies the relationship of real variables and processes nominal variables with CPI of China and the U.S. Table 1 shows a list of the initial variables related to model variables. Data sources are Wind, CEIC, BIS, and Bloomberg. China implemented housing monetization reform from 1998, and this paper chooses 1999 as the sample start period. Considering data length and continuity, housing price calculated according to commodity building selling value in China and commodity building selling area in China is the optimal agent variable for housing prices in China. The data of 70 large and medium-sized cities housing prices that need to be stitched is used to test for robustness.

Table 1: Initial variables and time interval

\begin{tabular}{clc}
\hline NO. & \multicolumn{1}{c}{ Variables } & Time interval \\
\hline 1 & commodity bldg selling value in China & $1999-01: 2019-12$ \\
2 & commodity bldg selling area in China & $1999-01: 2019-12$ \\
3 & China consumer price index (CPI of MoM) & $1999-01: 2019-12$ \\
4 & U.S. consumer price index (CPI of MoM) & $1999-01: 2019-12$ \\
5 & foreign exchange of PBOC & $1999-12: 2019-12$ \\
6 & foreign exchange rate: PBOC: month end : RMB to USD & $1999-01: 2019-12$ \\
7 & foreign exchange rate: PBOC: month average : RMB to USD & $1999-01: 2019-12$ \\
8 & non-deliverable forwards (NDF): daily : RMB to USD & $1999-01: 2019-12$ \\
9 & U.S. news_based economic policy uncertainty index & $2000-01: 2019-12$ \\
10 & new residential housing price of 70 large and medium-sized & $2005-07: 2017-12$ \\
& cities in China \\
11 & new commodity residential housing price of 70 large and & $2011-01: 2019-12$ \\
& medium-sized cities in China & \\
\hline
\end{tabular}

The foreign exchange rate of RMB to USD is preferred to other bilateral exchange rates because the U.S. dollar has a strong position in the international settlement, is tied closely with China-U.S. trade, and has an obvious correlation with the foreign exchange of PBOC. This paper uses the end value of the foreign exchange rate to convert currency and uses the average value to smooth out outliers and regressions. The Chinese government implemented foreign exchange control policies and can intervene indirectly with exchange rate fluctuations. As the RMB's influence and NDF trading volume in the offshore market increase, NDF quotations can reflect increasingly the foreign investors' expectations in RMB. Referring to Zhu et al. (2010) and Tan et al. (2013), this paper uses a "1-Year NDF Real Exchange Rate of RMB to USD" to divide the "Average Real Exchange Rate of RMB to USD" and minus one to represent the RMB exchange rate expectation.

Considering the potential effect of exchange rate expectations on current and capital accounts, the controversial scope of "hot money" in traditional literature, and "hot money" disguised as normal trade, this paper chooses foreign exchange of PBOC rather than a current account, capital account, or hot money as the explanatory variable. The foreign exchange of PBOC is more exogenous than M2 used as the growth rate target of the money supply. Data are segmented from December 31, 2008 after referring to Steven Wei Ho et al. (2017) combined with the development trend of the sub-prime crisis. 


\subsection{Test description}

The paper finds only the housing prices need to be adjusted after using the U.S. Census Bureau X13 seasonality test method. This paper takes the logarithm of real foreign exchange of $\mathrm{PBOC}$, named $\ln \left(f_{-}\right.$exchange $)$to reduce the probability of heterogeneous variance. After seasonality adjustment, this paper uses the unilateral HP filter to separate the cyclical and trend parts of housing prices and

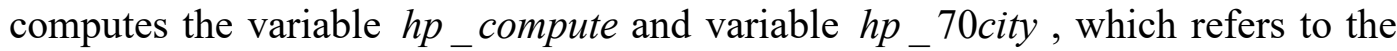
mean deviation percent from their steady-state. Table 2 shows the Ng-Perron unitroot test of five variables and their difference variables. $\triangle E x_{-}$rate_expect, $\Delta l n\left(f \_\right.$exchange $), h p \_c o m p u t e, E p u_{-} U S A$, and $h p \_70$ city are stationary sequences, while Ex_rate_expect or $\ln \left(f \_\right.$exchange $)$is not.

Table 2: Ng-Perron unit-root test

\begin{tabular}{|c|c|c|c|c|}
\hline Variable & MZa & $\mathbf{M Z t}$ & MSB & MPT \\
\hline Ex_rate_expect & -1.34924 & -0.75694 & 0.56101 & 16.4644 \\
\hline$\Delta E x_{\text {_rate }}$ expect & $-19.3994 * * *$ & $-3.08945 * * *$ & $0.15925^{* * *}$ & $1.35327 * * *$ \\
\hline $\ln \left(f_{-}\right.$exchange $)$ & -0.64525 & -0.40656 & 0.63008 & 22.8245 \\
\hline$\Delta \ln \left(f_{\text {_exchange }}\right)$ & $-7.98045^{*}$ & $-1.98027 * *$ & $0.24814^{*}$ & $3.13621 * *$ \\
\hline hp_compute & $-28.2367 * * *$ & $-3.75675 * * *$ & $0.13304 * * *$ & $0.86989 * * *$ \\
\hline$\Delta h p \_$compute & $-2681.02 * * *$ & $-36.6128 * * *$ & $0.01366^{* * *}$ & $0.00920 * * *$ \\
\hline$E p u_{-} U S A$ & $-21.7254 * * *$ & $-3.29068 * * *$ & $0.15147 * * *$ & $1.14591 * * *$ \\
\hline$\triangle E p u_{-} U S A$ & $-40.8991 * * *$ & $-4.52001 * * *$ & $0.11052 * * *$ & $0.60493 * * *$ \\
\hline$h p_{-} 70$ city & $-13.6094 * *$ & $-2.42984 * *$ & $0.17854 * *$ & $2.47241 * *$ \\
\hline$\Delta h p_{-} 70$ city & $-27.5781 * * *$ & $3.67788 * * *$ & $0.13336 * * *$ & $1.00230 * * *$ \\
\hline
\end{tabular}

Note. Significant level of $10 \%, 5 \%, 1 \%$ are marked by $* * *$, and $* * *$ respectively.

This paper regresses Formula 1 in different sample intervals, including 2000Q12008Q4 and 2009Q1-2019Q4. The residuals of both VAR models meet the normal distribution, have no heterogeneous variance and no auto-correlation. The optimal lag period of the two VAR models is 1 and 3, respectively. Both models have good statistical inference attributes. Relevant tests are shown below. Lag length and lag exclusion test represent the ranges of lag structure. Jarque-Bera, skewness, kurtosis test, heteroskedasticity, and serial correlation tests are related to the VAR residual test. The Adj. R-squared of the housing price as the explained variable of Formula 1 before 2009 is 0.201324 , and 0.526775 after 2009 . 
Table 3: VAR lag structure and residual tests of Formula 1

\begin{tabular}{|c|c|c|}
\hline Sample intervals & 1999Q1-2008Q4 & 2009Q1-2019Q4 \\
\hline Lag length criteria & $\begin{array}{l}\mathrm{SC} / \mathrm{LR} / \mathrm{HQ} / \mathrm{FPE} / \mathrm{AIC} \\
\mathrm{lag}=1\end{array}$ & $\begin{array}{l}\text { FPE/AIC best lag=3; } \\
\text { HQ/LR best lag=2; SC } \\
\text { best lag=1; Referring to } \\
\text { the results of normal } \\
\text { distribution, get lag=3 }\end{array}$ \\
\hline Lag exclusion wald join test & $\begin{array}{l}\text { no redundancy at the } 1 \% \\
\text { of significance level }\end{array}$ & $\begin{array}{l}\text { no redundancy at the } 5 \% \\
\text { of significance level }\end{array}$ \\
\hline $\begin{array}{l}\text { Jarque-Bera test } \\
\text { H0: normal distribution }\end{array}$ & $\mathrm{P}=0.7746$, no reject $\mathrm{H} 0$ & $\mathrm{P}=0.7552$, no reject $\mathrm{H} 0$ \\
\hline $\begin{array}{l}\text { Skewness test } \\
\mathrm{H} 0: E\left(\mathrm{~m}^{3}\right)=0\end{array}$ & $\mathrm{P}=0.8458$, no reject $\mathrm{H} 0$ & $\mathrm{P}=0.7450$, no reject $\mathrm{H} 0$ \\
\hline $\begin{array}{l}\text { Kurtosis test } \\
\mathrm{H} 0: E\left(\mathrm{~m}^{4}-3\right)=0\end{array}$ & $\mathrm{P}=0.4839$, no reject $\mathrm{H} 0$ & $\mathrm{P}=0.5355$, no reject $\mathrm{H} 0$ \\
\hline $\begin{array}{l}\text { Heteroskedasticity Tests } \\
\text { H0: No Cross Terms } \\
\text { (only levels and squares) }\end{array}$ & $\mathrm{P}=0.4240$, no reject $\mathrm{H} 0$ & $\mathrm{P}=0.2334$, no reject $\mathrm{H} 0$ \\
\hline $\begin{array}{l}\text { Heteroskedasticity Tests } \\
\text { H0: Includes Cross Terms }\end{array}$ & $\mathrm{P}=0.5307$, no reject $\mathrm{H} 0$ & / \\
\hline $\begin{array}{l}\text { Serial Correlation LM Tests } \\
\text { H0: no Serial Correlation }\end{array}$ & $\begin{array}{l}\text { When lag }=1 \text {, } \\
\mathrm{P}=0.5645 \text {, no reject } \mathrm{H} 0\end{array}$ & $\begin{array}{l}\text { When lag }=3 \text {, } \\
\mathrm{P}=0.6655 \text {, no reject } \mathrm{H} 0\end{array}$ \\
\hline
\end{tabular}

Table 4 shows two VAR models of Formula 1 Granger causality tests. Housing price and change in RMB exchange rate expectation are the Granger causalities for each other in 2009Q1-2019Q4. Before 2009, housing price represents the Granger causality of the change of RMB exchange rate expectation, but the opposite is not.

Table 4: VAR Granger causality tests of Formula 1

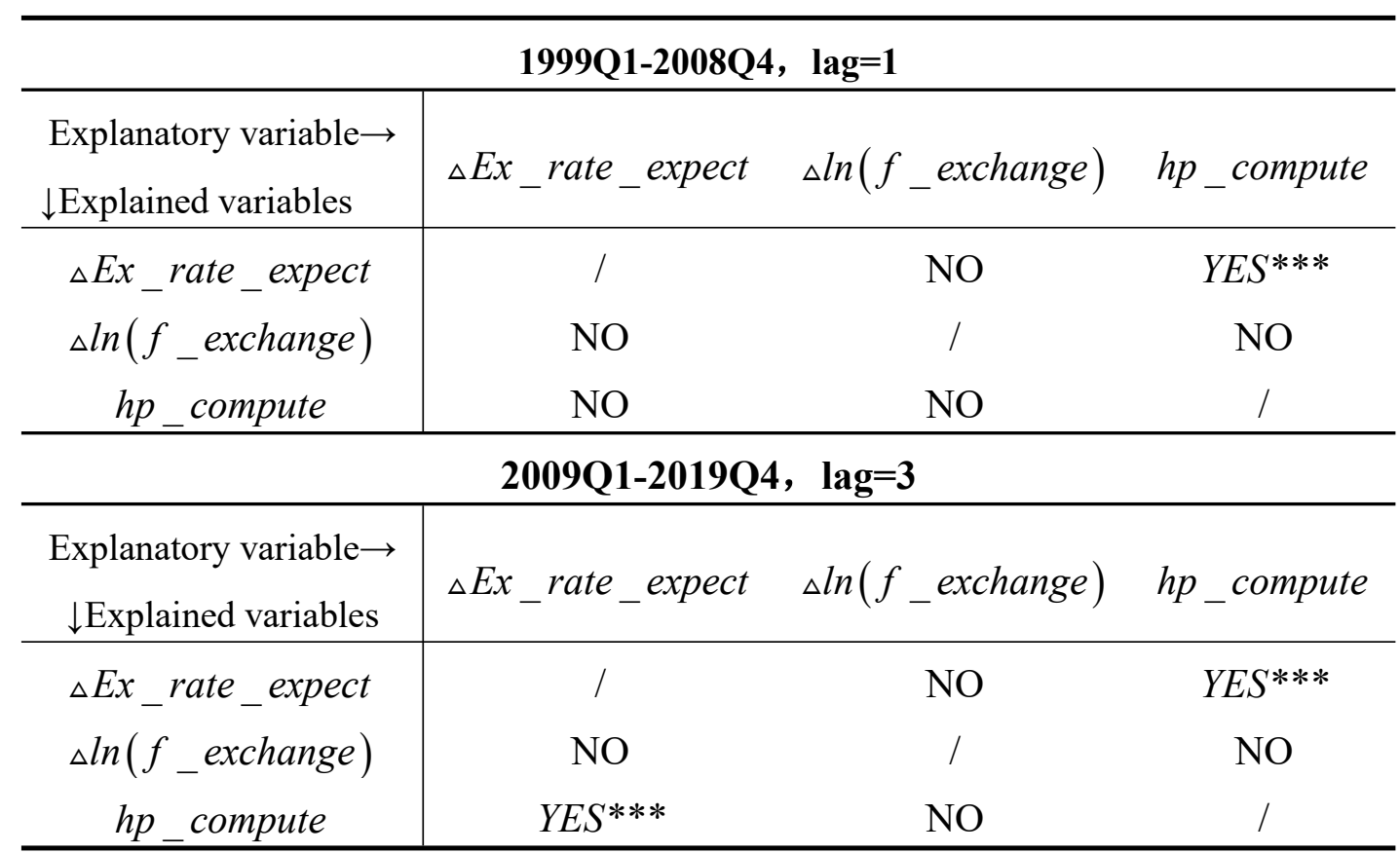

Note. Significant level of $10 \%, 5 \%, 1 \%$ are marked by $*, * *$, and $* * *$ respectively. 


\subsection{Impulse response and variance decomposition}

Before 2009, housing prices responded negatively initially under the positive effect of exchange rate expectation change. After 2009, housing price responded positively to the same impulse at the beginning. Figures 2 to 5 show the relative impulse using 1000 repetitions of Monte Carlo simulation.
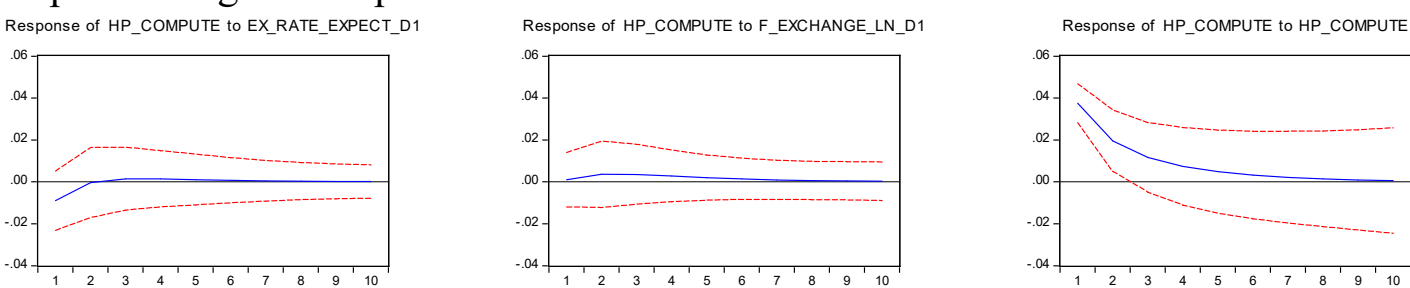

Figure 2: Response of housing price to three shocks (2000Q1-2008Q4) of Formula 1 (Cholesky dof adjusted)
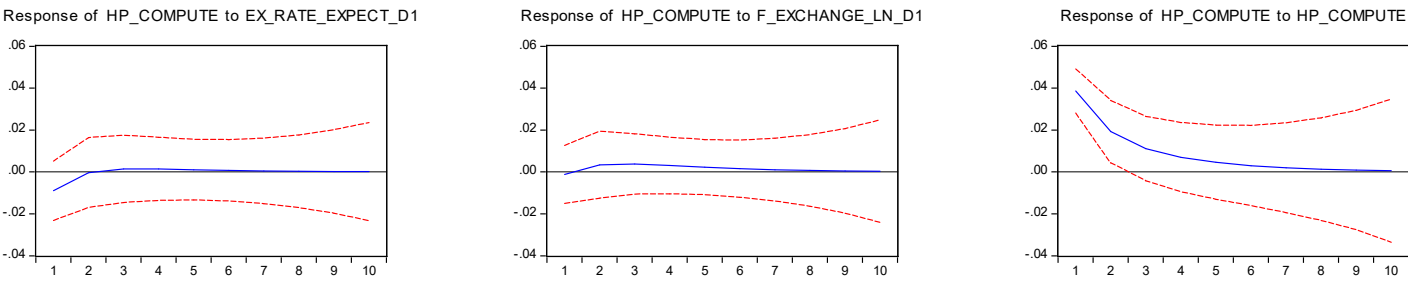

Figure 3: Response of housing price to three shocks (2000Q1-2008Q4) of Formula 1 (Generalized impulse)
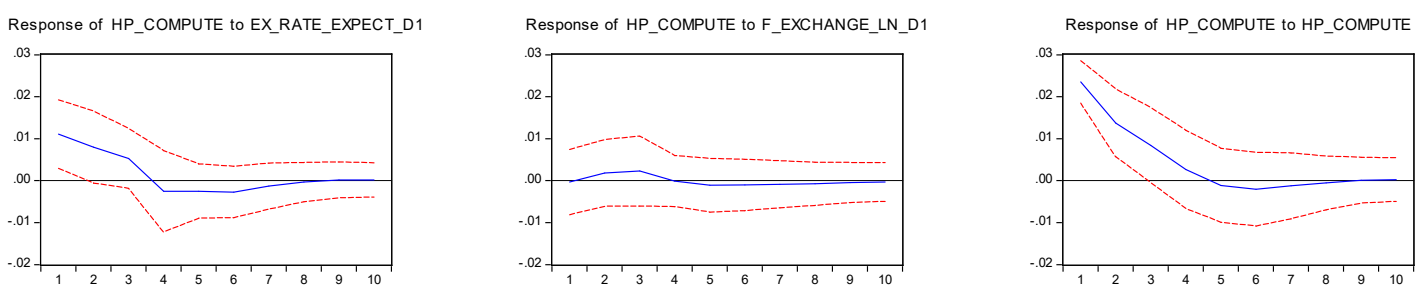

Figure 4 :Response of housing price to three shocks (2009Q1-2019Q4) of Formula 1 (Cholesky dof adjusted)
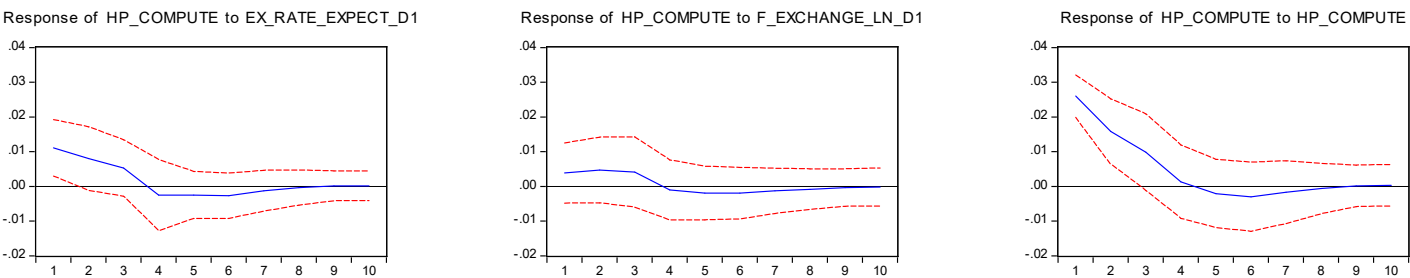

Figure 5: Response of housing price to three shocks (2009Q1-2019Q4) of Formula 1 (Generalized impulse)

Before 2009, the fluctuations in housing prices are explained by its innovation and the innovation of the change in RMB exchange rate expectation. The explanatory powers are $95 \%$ and $4 \%$, respectively. After 2009 , the explanatory power of exchange rate expectation change innovation improves to $22 \%$. Figures $6-7$ use 1000 repetitions of Monte Carlo simulation. 

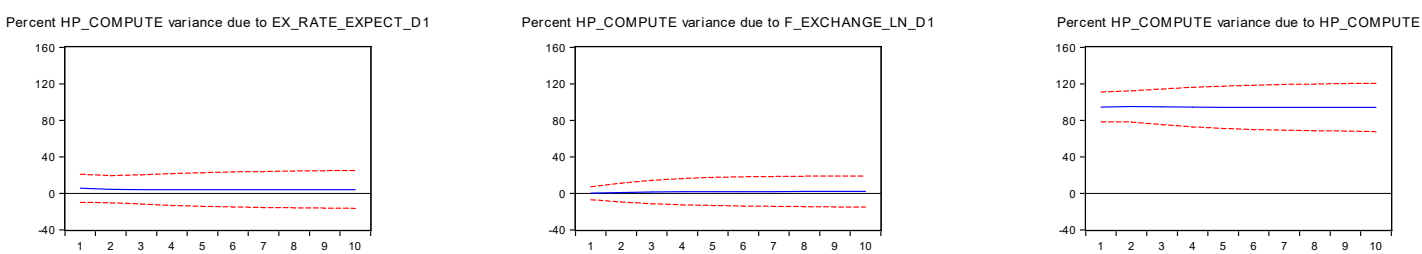

Figure 6: Variance decomposition of housing price (2000Q1-2008Q4) of Formula 1
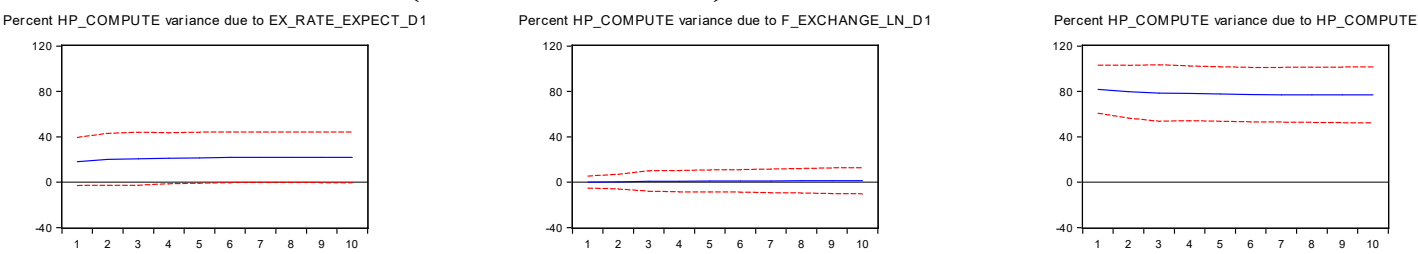

Figure 7: Variance decomposition of housing price (2009Q1-2019Q4) of Formula 1

Referring to Steven Wei Ho et al. (2017), Table 5 shows the relative variance decomposition of housing prices between 2009Q1-2019Q4 and 2000Q1-2008Q4. After 2009, the fluctuations in housing prices weakened to about $70 \%$ of fluctuations before 2009. However, the explanatory power of the change in RMB exchange rate expectation strengthened after 2009 to five times more than the previous rate.

Table 5: Relative variance decomposition of Formula 1

\begin{tabular}{ccccc}
\hline Period & S.E. & $\Delta E x_{-}$rate_expect & $\Delta \ln \left(f_{-}\right.$exchange $)$ & $h p \_$compute \\
\hline 1 & 0.67 & 3.34 & 0.25 & 0.87 \\
2 & 0.70 & 4.65 & 0.50 & 0.84 \\
3 & 0.71 & 5.06 & 0.65 & 0.83 \\
4 & 0.71 & 5.18 & 0.51 & 0.83 \\
5 & 0.70 & 5.29 & 0.53 & 0.82 \\
6 & 0.71 & 5.40 & 0.55 & 0.82 \\
7 & 0.71 & 5.41 & 0.58 & 0.82 \\
8 & 0.71 & 5.41 & 0.60 & 0.82 \\
\hline
\end{tabular}

\subsection{Robustness analysis}

\subsubsection{Replacing the housing price variable}

This paper uses $h p \_70$ city to replace $h p \_$compute to construct a VAR model as shown in Formula 2. When the sample is in 2009Q1-2019Q4, the optimal lag period is 2 . The residual meets the normal distribution, has no heterogeneous variance, has no auto-correlation, which means good statistical inference attributes. Adj. R-squared of the housing price as explained variable of Formula 2 is 0.684336 after 2009. The generalized impulse is similar to Cholesky dof adjusted impulse shown in Figure 8. Similar to Figures 4-5, housing price responses positively to RMB exchange rate appreciation expectation at the beginning. The explanatory power of the RMB exchange rate expectation change innovation to the fluctuations of the housing price is no higher than $9 \%$, which means the exchange rate expectation change has less influence on the housing prices of 70 large and medium-sized cities than on national average housing price in China. Both processes use 1000 repetitions of Monte Carlo simulation. The RMB exchange rate expectation is the Granger causality of the housing price. 

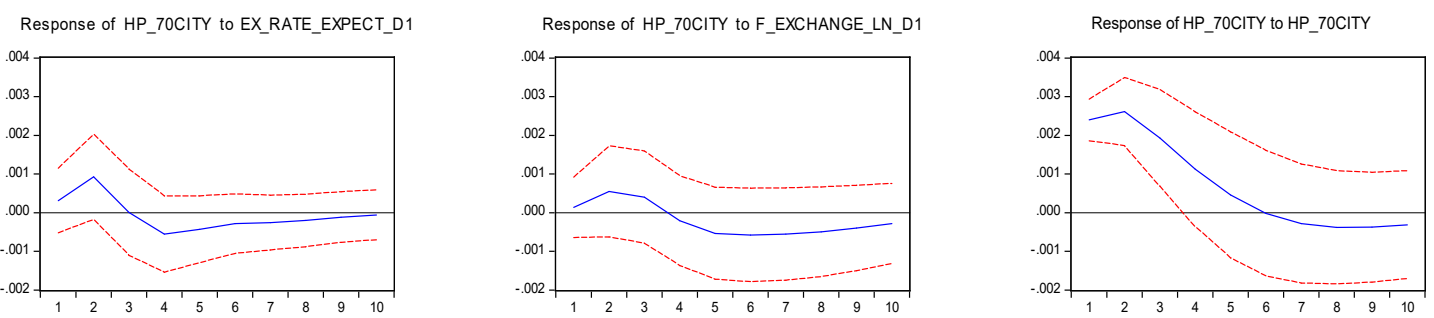

Figure 8: Response of housing price to three shocks (2009Q1-2019Q4) of Formula 2 (Cholesky dof adjusted)

Percent HP_70CITY variance due to EX_RATE_EXPECT_D1

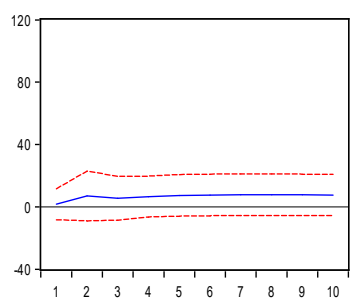

Percent HP_ 70CITY variance due to F_EXCHANGE_LN_D1

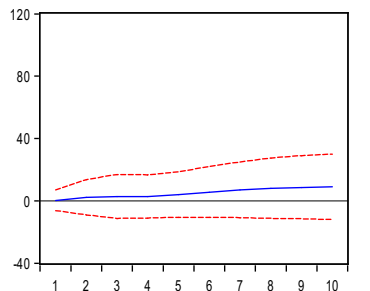

Percent HP_70CITY variance due to HP_70CITY

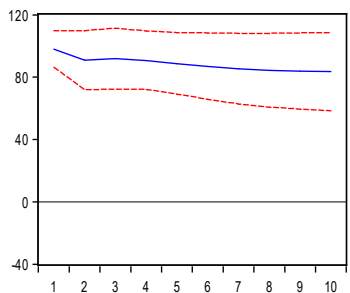

Figure 9: Variance decomposition of housing price (2009Q1-2019Q4) of Formula 2

\subsubsection{Introducing EPU into VAR model}

Maintaining $h p \_c o m p u t e$ as the agent variable, this paper introduces EPU to construct a VAR model as shown in Formula 3. When the sample is in 2009Q12019Q4, the optimal lag period is 2. The residual meets the normal distribution, has no heterogeneous variance, and no auto-correlation, which means good statistical inference attributes. The Adj. R-squared of the housing price as explained variable of Formula 3 is 0.471212 after 2009. The generalized impulse is similar to the Cholesky dof adjusted impulse shown in Figure 10. Similarly, housing prices responded positively to RMB exchange rate appreciation expectation at the beginning. When the U.S. economic policy uncertainty increased, housing prices responded negatively after a brief positive response. The explanatory power of RMB exchange rate expectation change innovation to fluctuations of the housing price is no more than $9 \%$, which is less than that when EPU is not introduced. Both processes use 1000 repetitions of Monte Carlo simulation. RMB exchange rate expectation is housing price 's Granger causality.
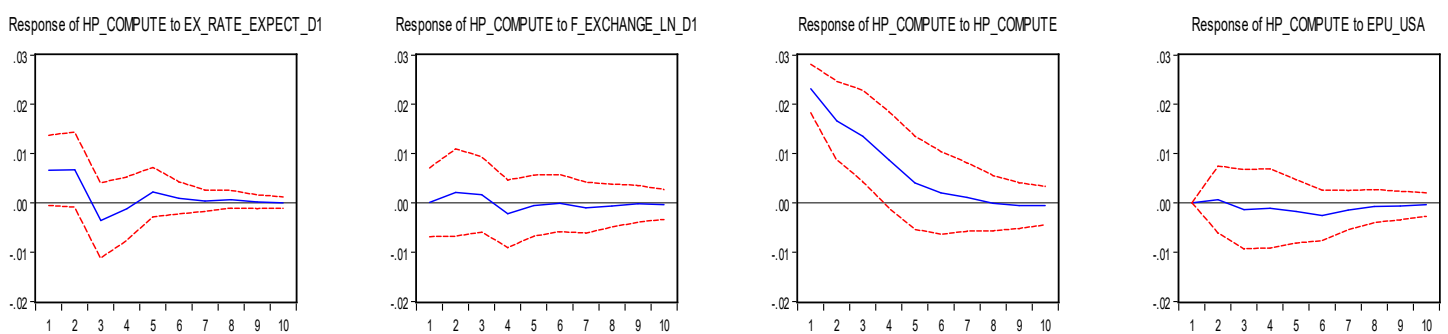

Figure 10: Response of housing price to four shocks (2009Q1-2019Q4) of Formula 3 (Cholesky dof adjusted) 

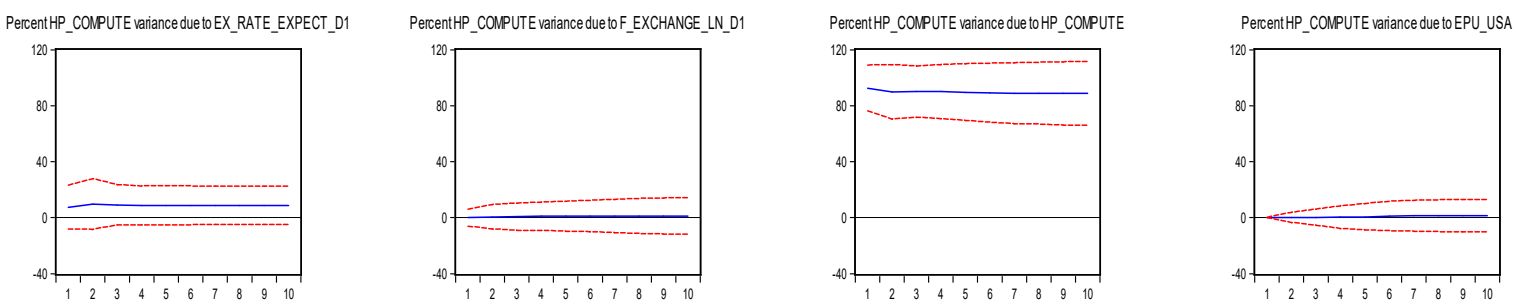

Figure 11: Variance decomposition of housing price (2009Q1-2019Q4) of Formula 3

\section{FAVAR model and extension analysis}

\subsection{Model principle and construction}

Bernanke et al. (2005) propose two methods of estimation on the FAVAR model. The first is the two-step method and the other is the Gibbs sampling method based on likelihood estimation. This paper chooses the two-step method to complete the empirical analysis because the computation cost of the two-step method is lower and the difference between the two methods is limited in qualitative analysis. Referencing Bernanke et al. (2005), Formula 4 and Formula 5 are important components of the FAVAR model. F represents some unobservable factors extracted from the model. Y represents some observable variables driving dynamic changes in the economy. X represents some observable macro-variables and has rich content. The model needs to identify factor $\mathrm{F}$ first to determine the changes of $X$ under the effect of Y's innovation. The effect of $F$ on $X$ and the effect of $\mathrm{Y}$ on $\mathrm{X}$ in turn can be obtained by determining the effect of $\mathrm{Y}$ on $\mathrm{F}$. Finally, the complete changes of $\mathrm{X}$ can be obtained.

The key step in finding the F fitting value is as follows: (1) Subdivide X composition into fast and slow variables that differ in terms of effect response. Process all data of the variables to be stationary. (2) Using the principal component analysis, extract the main component X1 from X, and X2 from the slow variables of $\mathrm{X}$. (3) Taking $\mathrm{Y}$ and $\mathrm{X} 2$ as explanatory variables, perform OLS when each variable of $\mathrm{X} 1$ is an explained variable. (4) Determine the fitting variable of each factor by using each variable of $\mathrm{X} 1$ and subtract the production of $\mathrm{Y}$ and the corresponding coefficient estimated value. This paper incorporates a change in RMB exchange rate expectation (corresponding variable $\Delta E x_{\text {_ }}$ rate_expect ), the degree of deviation from the steady-state of national average housing price in China (corresponding variable $h p$ _compute), and the change in interest rate spread between China and the U.S. (corresponding variable $\triangle R \_C N_{-} U S A$ ) into $\mathrm{Y}$. $\mathrm{X}$ includes the remaining domestic and foreign economic variables. The number of factors is determined by the cumulative contribution of principal component analysis. From the following text, this paper chooses five factors to refine Formula 4, which is shown as Formula 6. This paper proposes Formula 6 to examine the Hypothesis II and Hypothesis III.

$$
\begin{aligned}
& \left(\begin{array}{c}
\mathrm{F}_{t} \\
\mathrm{Y}_{t}
\end{array}\right)=\Phi(L) \times\left(\begin{array}{c}
\mathrm{F}_{t-1} \\
\mathrm{Y}_{t-1}
\end{array}\right)+\xi_{t} \\
& \mathrm{X}_{t}=\Lambda^{\mathrm{f}} \times \mathrm{F}_{t}+\Lambda^{y} \times \mathrm{Y}_{t}+\delta_{t}
\end{aligned}
$$




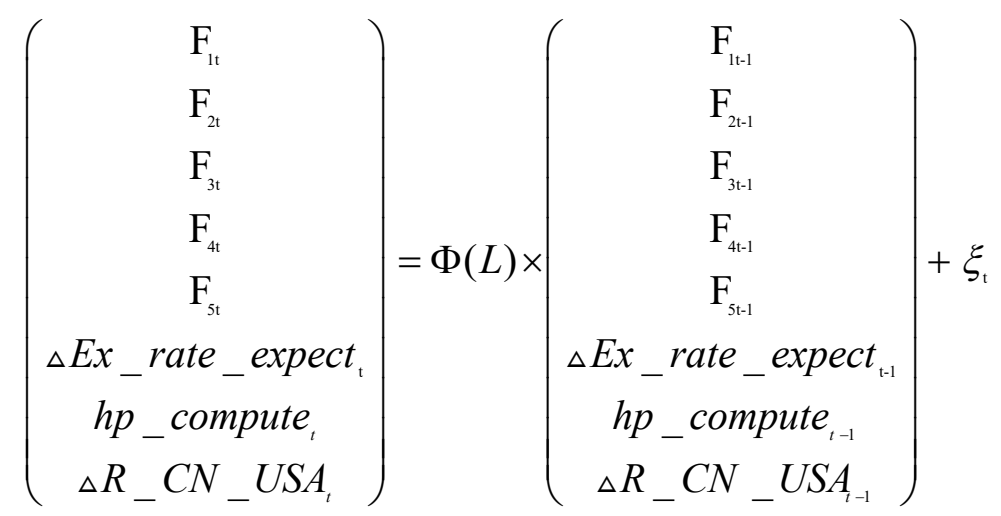

\subsection{Variables selection and procession}

The data sources of the FAVAR model are CEIC, Wind, and the official websites of relevant departments of China and the U.S. China has 12 classes of economic variables, including domestic production, employment, investment, price, the balance of international payments, exchange rate, real estate, capital market, interest rate, central bank policies, fiscal revenue and expenditure, and macro expectation. The reasons for choosing the above variables are as follows.

Real estate has a financial attribute and the real estate market development drives the development of its downstream industry. Real estate investment is an important part of fixed asset investment, which has a multiplier effect on GDP. The rise in housing prices results in the rise in prices, giving rise to the wealth effect of the residents who have already bought houses, but also may lead to the crowding-out effect of residents who want to save money to buy houses. The real estate market cannot be separated from the capital support of banks and non-bank financial institutions. The real estate market is an important target of China's macroeconomic regulation and control. Monetary policy making and market interest rates also consider the real estate market change, which may affect residents' expectations. China's unique land finance also depends on the development of the real estate market. The U.S. is an important trading partner of China, and its policy and economic changes have a profound effect on China's economy.

This paper selects monthly data directly because the frequency conversion of data is influenced by subjective processing, which leads to useful information loss. Referring to Fernald et al. (2014), this paper processes the Chinese New Year effect, X13 seasonality test and adjustment, and unit-root test (ADF, NP, KPSS) for all variables. Chinese New Year is usually in January or February. This paper supposes the growth rate of derived value at the end of January is equal to that at the end of February. This paper does not deal with nominal variables to real variables in the FAVAR model except for housing prices and exchange rate expectations. The FAVAR model involves 134 variables. The list of variables excluded $\Delta E x_{2}$ rate_expect, $h p_{-}$compute, and $\Delta R_{-} C N_{-} U S A$, and treatment points are shown in the Appendix. This paper extracted five principal component factors from $\mathrm{X}$ and the slow variables of $\mathrm{X}$, whose explanatory power to $\mathrm{X}$ and the slow variables of $\mathrm{X}$ is $37.35 \%$ and $47.90 \%$, respectively. 


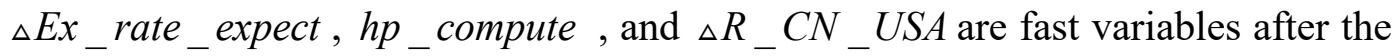
five factors in turn. The reason for the variable order of the FAVAR model is as follows. $\triangle E x_{\text {_rate }}$ expect is related to the current and capital accounts. Capital flows affect the fluctuation of housing prices, which respond to exchange rate expectations. Hence, $h p_{-}$compute is after $\Delta E x_{\text {_ }}$ rate_expect. The real estate market is related to people's lives and domestic monetary policy under the interest rate marketization responses to the fluctuations of housing prices. Considering the integration of the world economy, interest rate spread changes between China and the U.S. will respond to changes in exchange rate expectations and fluctuations in housing prices. Hence, $\triangle R_{-} C N_{-} U S A$ is after $h p_{-}$compute . Due to the EM iteration method 's non-applicability for long-missing data, This paper chooses a sample period from November 2006 to December 2018 to remove data availability. The lag length of this FAVAR model is 1 based on the lag length criteria.

\subsection{Variance decomposition and factor implications}

This paper decomposes the variance of the FAVAR model using Cholesky order similar to Formula 6 and uses 1000 repetitions of Monte Carlo simulation. The effect of the innovations of the RMB exchange rate expectation change on fluctuations of housing price after 2009 is more than the interval of 2006 M11-2018 M12, whose explanatory power is $18 \%$ and $10 \%$, respectively . It shows that the change in exchange rate expectation has a stronger effect on the fluctuations of housing prices after the sub-prime crisis. In the interval of 2006 M11-2018 M12, the explanatory power of housing price inertia, Factors $1,2,3$, and 5 maintain $49 \%, 7 \%, 27 \%, 3 \%$, and $4 \%$ in the long term simulation, respectively. The explanatory powers of Factor 4 and interest rate spread change between China and the U.S. is less than $1 \%$. Considering the relatively important Factors 1, 2, and 5, figure 13 shows the trend in the interval of the entire sample.
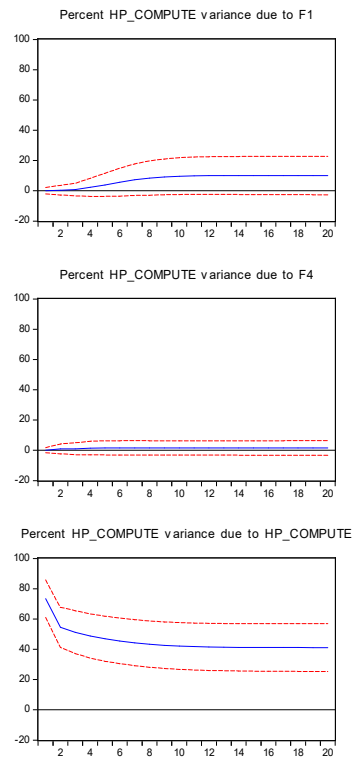

Figure 12: Variance decomposition of housing price ( 2006M11-2018M12) of Formula 6 (Cholesky dof adjusted) 
F1

F2

F5

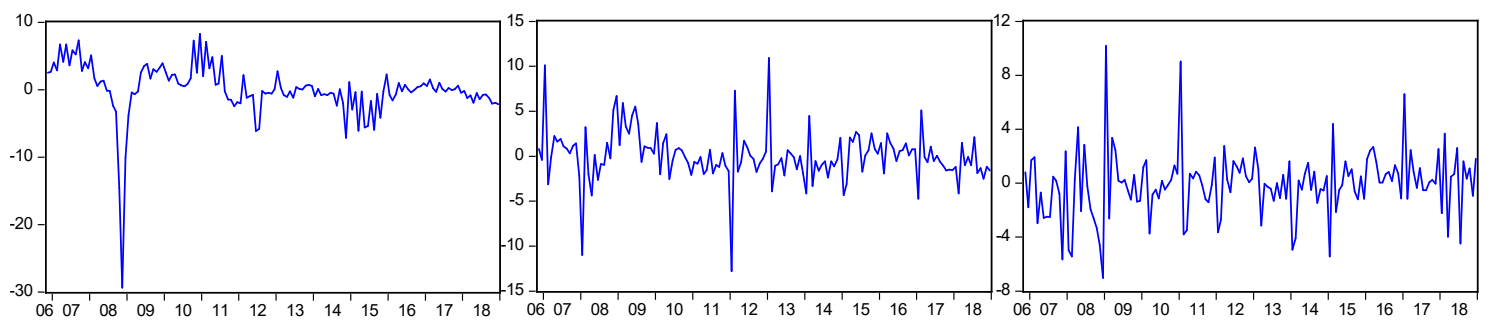

Figure 13: Trend of factors 1, 2, and 5 of the FAVAR model (2006M11-2018M12)

The paper uses all variables to identify the correlation with five factors and selects the variable meaning of the correlation relationship greater than or equal to 0.5 as the meaning of the related factor as detailed in the following table.

Table 5: Meanings of five factors that refer to the correlation relationship

\begin{tabular}{l|l}
\hline Factor & \multicolumn{1}{c}{ Meaning } \\
\hline Factor 1 & $\begin{array}{l}\text { Medium- and long-term interest rates, production climate } \\
\text { degree, prices, and expectations } \\
\text { Note. Variables whose correlation with Factor 1 is greater } \\
\text { than or equal to 0.5, include central bank benchmark } \\
\text { interest rate, savings rate, loan interest rate, PE ratio, PMI, } \\
\text { re-discount rate, medium-term and long-term inter-bank } \\
\text { lending rate, CPI, export delivery value, and exchange rate } \\
\text { expectations. }\end{array}$ \\
\hline Factor2 & $\begin{array}{l}\text { Production and sales of automobiles, real estate sales, and } \\
\text { money supply M1 }\end{array}$ \\
\hline Factor3 & Foreign exchange of PBOC, employment \\
\hline Factor4 & Production and sales of automobiles, currency swap, M1 \\
\hline Factor5 & $\begin{array}{l}\text { No variable has a correlation with Factor 5 greater than or } \\
\text { equal to 0.5. Variables whose correlation with Factor 5 is } \\
\text { between 0.3 and 0.4 include real estate sales, prices, CPI, } \\
\text { money supply and trade balance. }\end{array}$ \\
\hline
\end{tabular}




\subsection{Impulse response and analysis}

Re sporse of HP_COMPUTE D F1

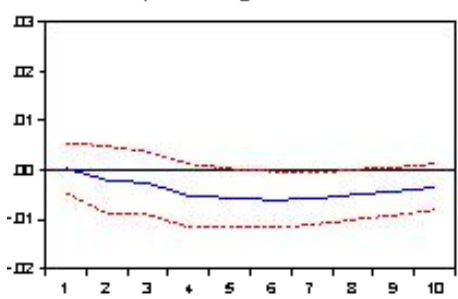

Resporse of HP_COMPUTE D FA

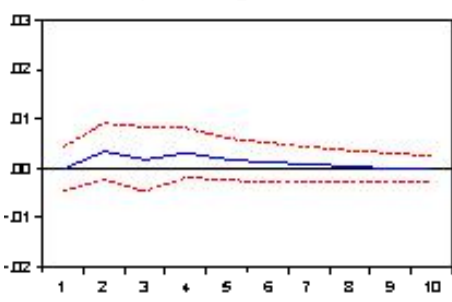

Res poise of HP_COMPUTE D HP_COMPUTE

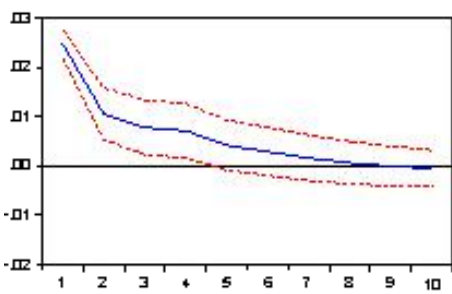

Respoise of HP_COMPUTE D F2

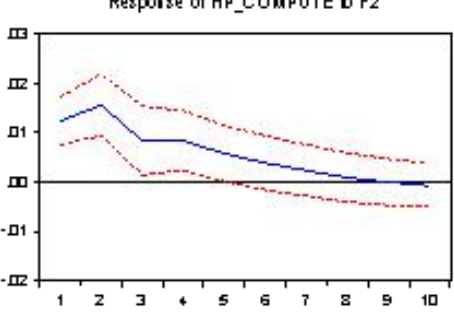

Resporse of HP_COMPUTE D FS

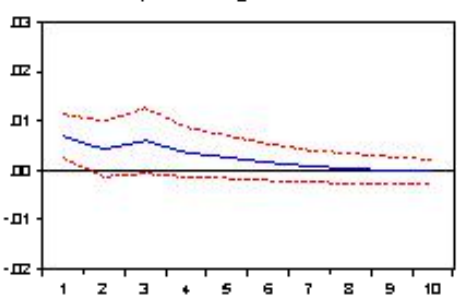

Resporse of HP_CO MPUTE D R_CN_USA_D1

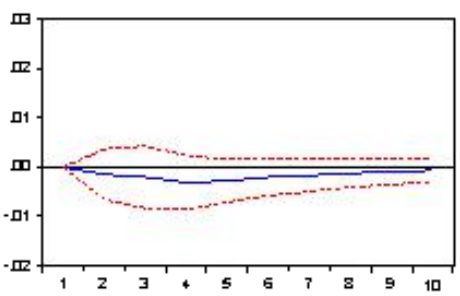

Resporse of HP_COMPUTE to F3

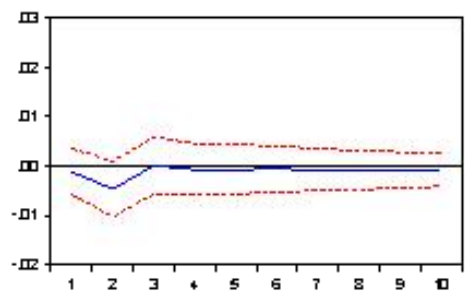

Re spouse of HP_CO MPUTE D EX_RATE_EXPECT_D1

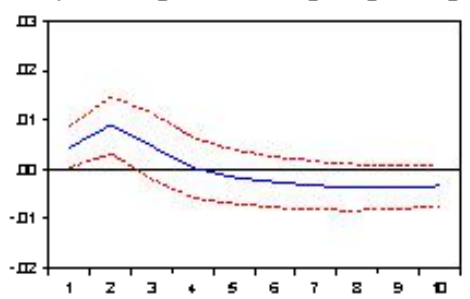

Figure 14: Impulse response of housing price

(2006M11-2018M12) of Formula 6 (Cholesky dof adjusted)

In the interval of 2006M11-2018M12, the housing prices respond in the first four periods positively when the RMB exchange rate appreciation expectation appears. The housing prices respond positively to their innovation. Housing prices recover gradually after a small negative reaction when the interest rate spread change between China and U.S. increases. Factor 1 refers mainly to medium-term and long-term interest rates, when the cost of investment and financing increases, housing prices respond negatively. Factor 2 refers mainly to durable goods production, sale and M1, when the demand for durable goods increases or the money supply increases and housing prices respond positively. The meaning of Factor 5 is mixed when real estate sales increase, or CPI increases, or money supply increases or trade surplus, housing prices are stimulated and show a positive response. Factor 2 contains liquidity information, when market liquidity increases and housing prices are raised.

\subsection{Source analysis of exchange rate expectations}

$$
\begin{aligned}
& E x_{-} r a t e_{-} \text {expect } t_{\mathrm{t}}=d_{1} E x_{-} \text {rate_expect } t_{\mathrm{t}-1}+d_{2} R_{-} c{ }_{-}{ }_{-} u s a_{t} \\
& d_{3} E p u_{-} U S A_{t-1}+d_{4} \Delta F \text { _exchange_M } M 2_{t}+\kappa_{\mathrm{t}}
\end{aligned}
$$

This paper proposes Formula 7 to examine the Hypothesis IV.The VAR and FAVAR models show that the change in RMB exchange rate expectation is an important explanatory variable for housing price fluctuation. The RMB exchange rate expectation is filtered by the unilateral HP filter. This paper names the cycle part as Ex_rate_expect and searches for variables that explain exchange rate 
expectations around the cycle part. Figure 15 shows the recursive coefficients that indicate that the estimation is stable. In the interval of 2009M01-2019M12, the residuals of OLS have first order self-correlation but meet the normal distribution and have no heterogeneous variance. The regression conclusion is as follows. Previous RMB exchange rate expectations, interest rate spread between China and U.S., EPU of U.S., and the ratio of foreign exchange of PBOC to M2 can explain the RMB exchange rate expectations.

The economic implications of the estimated parameters are as follows: (1) Exchange rate expectation has higher inertia (approximately 0.73). (2) Interest rate spread between China and U.S. affects exchange rate expectation; local currency appreciation indicates that the spread is positive. From the perspective of interest rate parity, the forward value of the local currency tends to depreciate, which means the coefficient of $R_{-} c n_{-} u s a$ is negative. (3) As uncertainty about the U.S. economic policy increases, the relative safety of China assets creates expectations of exchange rate appreciation. (4) The positive growth rate of foreign exchange that is faster than M2 and the negative growth rate of foreign exchange that is slower than M2 can lead to the ratio of foreign exchange of PBOC to M2 increase. The increase of the ratio means less liquidity in China, RMB facing the pressure of appreciation, and the coefficient of $\Delta F$ _exchange_ $M 2$ is positive. In terms of monetary policy options, the domestic interest rate increases may lead to a decline in housing prices. The PBOC can adjust exchange rate expectations through appropriate sterilizing intervention, which is reflected indirectly by the ratio of foreign exchange of PBOC to M2 and affect housing prices in China.

$$
\begin{array}{cc}
\text { Ex_rate_expect } t_{\mathrm{t}}= & 0.732564 * E_{-} x_{-} \text {rate_expect } t_{\mathrm{t}-1}-0.370695 * R_{-} c n_{-} u s a_{t} \\
(0.038543) & (0.189213) \\
{[19.00643]} & {[-1.959140]} \\
+(2.54 E-05) * E p u \_U S A_{t-1}+ & 0.429618 * \Delta F_{-} \text {exchange_M2 } 2_{t} \\
(6.97 \mathrm{E}-06) & (0.183824) \\
{[3.652182]} & {[2.337115]}
\end{array}
$$

Note. Standard errors are in parentheses, t-test values are in square brackets, the significance of four estimated parameters above are $1 \%, 5 \%, 10 \%$, and $1 \%$, respectively. The adjusted R Square is 0.790202 .

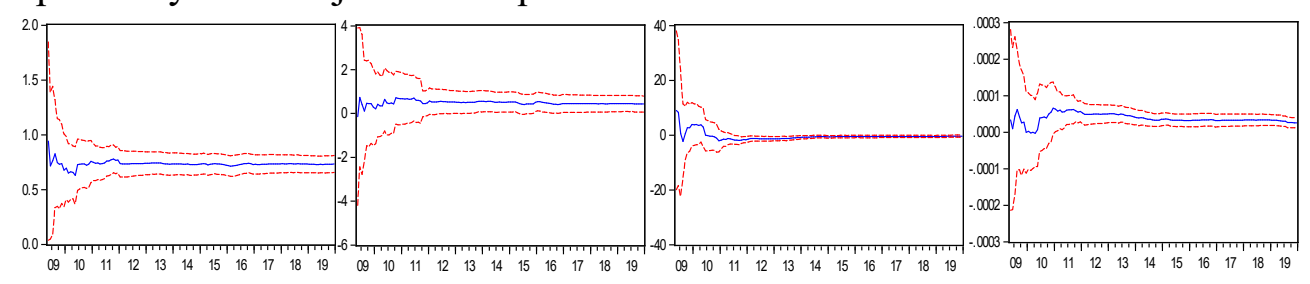

Figure 15: Recursive coefficients

(four estimated parameters $\mathrm{d} 1, \mathrm{~d} 2, \mathrm{~d} 3$ and $\mathrm{d} 4$ in order)

\section{Conclusion}

In 2015, the U.S. economy showed signs of recovery, while China's economy slowed down, and capital began to outflow obviously. "Guarantee housing price or 
exchange rate" became a hot issue. Existing literature focuses mainly on the study of stock price and exchange rate and the study of housing price and exchange rate. Studies on housing prices and exchange rate expectations at the same time are scarce. "Guarantee housing price or exchange rate" appears to be a dilemma that can be relieved from exchange rate expectation, especially by distinguishing between before and after the sub-prime crisis.

The VAR models constructed in this paper show good test results, whether EPU is included, using a new residential housing price of 70 large and medium-sized cities or the national average housing price in China as the agent variable of housing price.The empirical results show the exchange rate appreciation expectation before 2009 causes housing price to respond negatively and positively after 2009. Exchange rate expectation can explain more than $20 \%$ of the fluctuations of housing prices, which is about five times that of the fluctuation of housing prices before 2009. The change of RMB exchange rate expectation is not the Granger causality of housing prices before 2009. After 2009, the two are Granger causalities for each other. Housing prices affect the exchange rate expectation and vice versa, showing spiral rising state.

FAVAR model is an extension model of the VAR model, which can solve endogenesis very well. This paper shows the explanatory power of exchange rate expectations to housing prices' fluctuations by constructing a FAVAR model that includes 134 variables. At the same time, this paper finds several unobservable factors that have rich economic implications to explain the fluctuations of housing prices in China in the interval of 2006M01-2018M12. The empirical results of the OLS model show that the degree of Chinese government reversal intervention, interest rate spread between China and the U.S., and uncertainty of U.S. economic policy can explain the exchange rate expectation. This paper suggests that the government should control the degree of reversal intervention to affect the exchange rate expectation and realize the housing price control indirectly.

\section{References}

[1] Gao Bo and Mao Zhonggen, "Exchange rate shock and evolution of bubble of real estate: international experience and Chinese policy orientation," Economic Theory and Business Management, no. 7, 2006, pp.38-43.

[2] Wang Aijian and Shen Qingjie, "Study on the correlation between RMB exchange rate and real estate price," Journal of Financial Research, vol.342, no. 6, 2007, pp.13-22.

[3] Zhu Mengnan, Liu Lin and Ni Yujuan, "RMB exchange rate and real estate price in China: An empirical study based on Markov Regime Switching VAR model," Journal of Financial Research, vol.371, no.5, 2011, pp.58-71.

[4] Kuang Weida, "FDI and housing price," Economic Theory and Business Management, no.2, 2013, pp.51-58.

[5] Du Minjie and Liu Xiahui, "RMB expectation and real estate price changes," The Journal of World Economy, no.1, 2007, pp.81-88.

[6] Meng Qinbin and Rong Chen, "Long-term and short-term effects of macroeconomic factors on real estate prices," Statistical Research, no.6, 2014, pp.25-32. 
[7] Zhu Mengnan and Liu Lin, "Short -run International capital flows, exchange rate and asset prices: an empirical study based on data after exchange rate reform since 2005," Finance \& Trade Economics, no.5, 2010, pp.5-13.

[8] Tian Xiaofen and Lin Mucai, "An empirical study on the expectation of RMB appreciation and the change of real estate price in China," China Soft Science, no.8, 2013,pp. 55-66.

[9] Wang Bin and Tang Guoqiang, "Capital account opening, exchange rate policy and asset price," Modern Economic Science, no.1, 2016, pp.13-26.

[10] Dong Kai and Xu Chengming, "Interest rate distortions, real asset prices and exchange rate fluctuations," World Economy Studies, vol.284, no.10, 2017, pp.111-122.

[11] Deng Yongliang, "Appreciation of RMB, the fluctuation of RMB exchange rate and the control of the housing price," Research on Economics and Management, no.6, 2010, pp. 43-50.

[12] Wang Jiajia and Guo Hongyu, "The Influence of RMB Exchange Rate on China's Asset Price: An Empirical Analysis based on State Space Model,' Contemporary Economic Research, no.9, 2012, pp. 81-86.

[13] Liao Hui and Zhang Min, "Study on the linkage between RMB exchange rate and China's stock price and housing price," Review of Investment Studies, no.7, 2012, pp.108-117.

[14] Tan Zhengxun and Liu Shaobo, "Research on the fluctuation of housing price, the identification of monetary policy position and its reaction under the open condition in China," Journal of Financial Research, vol.419, no.5, 2015, pp.50-66.

[15] Zhong Chen, "Linkage effect of the RMB exchange rate, FDI and real estate prices under the New Normal: an empirical analysis of 25 provinces from 2005-2014," Reform of Economic System, no.6 , 2015, pp.144-151.

[16] Gai Jing, "Empirical test of the effect of China's exchange rate on the real economy through real estate price channels: VAR model analysis based on data after the 2005 exchange rate reform," Financial Theory \& Practice, vol.450, no.1, 2017,pp. 37-44.

[17] Ho Wei Steven, Zhang Ji and Zhou Hao, "Hot Money and Quantitative Easing: The Spillover Effects of U.S. Monetary Policy on the Chinese Economy," Journal of Money, Credit, and Banking, vol.50, no.7, 2017, pp.1543-1569.

[18] Ben S.Bernanke, Jean Boivin and Piotr Eliasz, "Measuring The Effects of Monetary Policy: A Factor-Augmented Vector Autoregressive (FAVAR) Approach," The Quarterly Journal of Economics, no.1, 2005.

[19] JG Fernald, MM Spiegel and ET Swanson, "Monetary policy effectiveness in China Evidence from a FAVAR model," Journal of International Money \& Finance, no.49, 2014, pp.83-103. 


\section{Appendix}

Variables without asterisks are from CEIC. All series are in monthly frequencies and all of data spans is from 2006M11 to 2018 M12. Each variable is assumed to be either fast moving or slow moving variable for the purpose of FAVAR estimation. This paper uses the U.S. Census Bureau 's X-13 method to process seasonality adjustment. SA means that variable needs to be adjusted and has been adjusted, while NS means not. Ln means logarithm, $\triangle$ means first difference, $\triangle$ Ln means first difference of logarithm, and NONE means no transformation.

\begin{tabular}{|c|c|c|c|c|c|}
\hline No. & Classification & Variable & $\begin{array}{l}\text { SA/ } \\
\text { NS }\end{array}$ & $\begin{array}{c}\mathbf{L n} / \triangle / \\
\triangle \mathbf{L n}\end{array}$ & $\begin{array}{l}\text { Fast } \\
\text { slow }\end{array}$ \\
\hline 1 & \multirow{16}{*}{$\begin{array}{l}\text { Domestic } \\
\text { production }\end{array}$} & CN: Retail Sales of Consumer Goods & SA & $\triangle \mathrm{Ln}$ & slow \\
\hline 2 & & CN: Industrial Sales Value: Delivery Value for Export & SA & $\triangle \mathrm{Ln}$ & slow \\
\hline 3 & & CN: Energy Production: Electricity & SA & $\triangle \mathrm{Ln}$ & slow \\
\hline 4 & & CN: Transport: Passenger Traffic & NS & $\triangle \mathrm{Ln}$ & slow \\
\hline 5 & & CN: Automobile: Sales & SA & $\triangle \mathrm{Ln}$ & slow \\
\hline 6 & & CN: Automobile: Sales: Domestic Made (DM) & SA & $\triangle \mathrm{Ln}$ & slow \\
\hline 7 & & CN: Automobile: Production & SA & $\triangle \mathrm{Ln}$ & slow \\
\hline 8 & & CN: Automobile: Production: Domestic Made (DM) & SA & $\triangle \mathrm{Ln}$ & slow \\
\hline 9 & & CN: Natural Gas Production & SA & $\triangle \mathrm{Ln}$ & slow \\
\hline 10 & & CN: Crude Oil Production & SA & $\triangle \mathrm{Ln}$ & slow \\
\hline 11 & & CN: Refined Crude Oil Production & $\mathrm{NS}$ & $\triangle \mathrm{Ln}$ & slow \\
\hline 12 & & CN: Gasoline Production & SA & $\triangle \mathrm{Ln}$ & slow \\
\hline 13 & & CN: Diesel Fuel Production & $\mathrm{NS}$ & $\triangle \mathrm{Ln}$ & slow \\
\hline 14 & & CN: Fuel Oil Production & SA & $\triangle \mathrm{Ln}$ & slow \\
\hline 15 & & CN: PMI: Mfg: Production & NS & NONE & slow \\
\hline 16 & & CN: PMI: Mfg: New Export Order & $\mathrm{NS}$ & $\mathrm{Ln}$ & slow \\
\hline 17 & \multirow{7}{*}{ Employment } & CN: No of Employee: Ferrous Metal Mining \& Dressing & SA & $\triangle \mathrm{Ln}$ & slow \\
\hline 18 & & CN: No of Employee: Wine, Beverage \& Refined Tea Manufacturing & SA & $\triangle \mathrm{Ln}$ & slow \\
\hline 19 & & CN: No of Employee: Textile & SA & $\triangle \mathrm{Ln}$ & slow \\
\hline 20 & & CN: No of Employee: Paper Making \& Paper Product & SA & $\triangle \mathrm{Ln}$ & slow \\
\hline 21 & & CN: No of Employee: Medical \& Pharmaceutical Product & NS & $\triangle \mathrm{Ln}$ & slow \\
\hline 22 & & $\begin{array}{l}\text { CN: No of Employee: Computer, Communication \& Other Electronic } \\
\text { Equipment }\end{array}$ & SA & $\triangle \mathrm{Ln}$ & slow \\
\hline 23 & & CN: No of Employee: Electrical Machinery \& Equipment & SA & $\triangle \mathrm{Ln}$ & slow \\
\hline 24 & \multirow{5}{*}{ Investment } & CN: Fixed Asset Investment: ytd & SA & $\triangle \mathrm{Ln}$ & slow \\
\hline 25 & & CN: FDI: Utilized: ytd: Joint Ventures & SA & $\triangle \mathrm{Ln}$ & slow \\
\hline 26 & & CN: FDI: Utilized: ytd (annual data included all finance) & SA & $\triangle \mathrm{Ln}$ & slow \\
\hline 27 & & CN: FDI: Utilized: ytd: Cooperative Ventures & NS & $\triangle \mathrm{Ln}$ & slow \\
\hline 28 & & CN: FDI: Utilized: ytd: Foreign Enterprises & SA & $\triangle \mathrm{Ln}$ & slow \\
\hline 29 & \multirow{6}{*}{ Price } & $\mathrm{CN}$ : Consumer Price Index & NS & $\triangle \mathrm{Ln}$ & slow \\
\hline 30 & & CN: CPI: Core (excl. Food \& Energy) & NS & $\triangle \mathrm{Ln}$ & slow \\
\hline 31 & & CN: CPI: non Food & NS & NONE & slow \\
\hline 32 & & CN: Retail Price: 36 City Avg: Fresh Pork: Refine Muscle & SA & $\triangle$ & slow \\
\hline 33 & & CN: Market Price: Monthly Avg: Oil Product: Diesel Oil, No 0 & NS & $\triangle \mathrm{Ln}$ & slow \\
\hline 34 & & CN: Settlement Price: Shanghai Futures Exchange: Fuel Oil: 1st Month & NS & $\triangle \mathrm{Ln}$ & slow \\
\hline 35 & \multirow{6}{*}{$\begin{array}{l}\text { The balance } \\
\text { of } \\
\text { international } \\
\text { payments }\end{array}$} & CN: Official Reserve Asset: Foreign Reserve(FR) & SA & $\triangle \mathrm{Ln}$ & fast \\
\hline 36 & & CN: Export FOB & SA & $\triangle \mathrm{Ln}$ & slow \\
\hline 37 & & CN: Import CIF & SA & $\triangle \mathrm{Ln}$ & slow \\
\hline 38 & & CN: Trade Balance & SA & $\triangle$ & slow \\
\hline 39 & & CN: Export FOB: Revised & SA & $\triangle \mathrm{Ln}$ & slow \\
\hline 40 & & CN: Import CIF: Revised & SA & $\triangle \mathrm{Ln}$ & slow \\
\hline
\end{tabular}




\begin{tabular}{|c|c|c|c|c|c|}
\hline 41 & & CN: Trade Balance: Revised & SA & $\triangle$ & slow \\
\hline 42 & & CN: Official Reserve Asset: Gold: Gold Reserve & NS & $\triangle \mathrm{Ln}$ & fast \\
\hline 43 & & CN: Monetary Authority: Liab: Reserve Money & SA & $\triangle \mathrm{Ln}$ & fast \\
\hline 44 & & CN: Monetary Authority: Liab: Reserve Money: Currency Issue & SA & $\triangle \mathrm{Ln}$ & fast \\
\hline 45 & & CN: Monetary Authority: Asset: Total & NS & $\triangle \mathrm{Ln}$ & fast \\
\hline 46 & & CN: Monetary Authority: Asset: Foreign Asset & NS & $\triangle \mathrm{Ln}$ & fast \\
\hline 47 & & CN: Monetary Authority: Asset: Foreign Asset: Gold & NS & $\triangle \mathrm{Ln}$ & fast \\
\hline 48 & & CN: Monetary Authority: Asset: Foreign Asset: Foreign Exchange & NS & $\triangle \mathrm{Ln}$ & fast \\
\hline 49 & \multirow{12}{*}{$\begin{array}{l}\text { Exchange } \\
\text { Rate }\end{array}$} & CN: FX Rate: PBOC: Month End: RMB to USD & NS & $\triangle \mathrm{Ln}$ & fast \\
\hline 50 & & CN: Effective Exchange Rate Index: BIS: Real & SA & $\triangle \mathrm{Ln}$ & fast \\
\hline 51 & & CN: Effective Exchange Rate Index: BIS: Nominal & NS & $\triangle \mathrm{Ln}$ & fast \\
\hline 52 & & CN: Currency Swap: USD: 1 Week: Bid & NS & $\triangle$ & fast \\
\hline 53 & & CN: Currency Swap: USD: 1 Week: Offer & NS & $\triangle$ & fast \\
\hline 54 & & CN: Currency Swap: USD: 1 Month: Bid & NS & $\triangle$ & fast \\
\hline 55 & & CN: Currency Swap: USD: 1 Month: Offer & NS & $\triangle$ & fast \\
\hline 56 & & CN: Currency Swap: USD: 3 Month: Bid & NS & $\triangle$ & fast \\
\hline 57 & & CN: Currency Swap: USD: 3 Month: Offer & NS & $\triangle$ & fast \\
\hline 58 & & CN: Currency Swap: USD: 6 Month: Offer & NS & $\triangle$ & fast \\
\hline 59 & & CN: Currency Swap: USD: 1 Year: Bid & NS & $\triangle$ & fast \\
\hline 60 & & CN: Currency Swap: USD: 1 Year: Offer & NS & $\triangle$ & fast \\
\hline 61 & \multirow{18}{*}{ Real Estate } & CN: Property Price: YTD Avg: Overall & SA & $\triangle \mathrm{Ln}$ & fast \\
\hline 62 & & CN: Property Price: YTD Avg: Residential: Overall & SA & $\triangle \mathrm{Ln}$ & fast \\
\hline 63 & & CN: Property Price: YTD Avg: Commercial Bldg: Overall & SA & $\triangle \mathrm{Ln}$ & fast \\
\hline 64 & & CN: Floor Space Started: ytd: Commodity Bldg (CB) & SA & $\triangle \mathrm{Ln}$ & slow \\
\hline 65 & & CN: Real Estate Inv: ytd & SA & $\triangle \mathrm{Ln}$ & slow \\
\hline 66 & & CN: Real Estate Inv: Source of Fund: ytd: Other & SA & $\triangle \mathrm{Ln}$ & slow \\
\hline 67 & & CN: Real Estate Inv: Source of Fund: ytd: Self Raised & SA & $\triangle \mathrm{Ln}$ & slow \\
\hline 68 & & CN: Real Estate Inv: Source of Fund: ytd: Foreign Inv & SA & $\triangle \mathrm{Ln}$ & slow \\
\hline 69 & & CN: Real Estate Inv: Source of Fund: ytd: Domestic Loan & SA & $\triangle \mathrm{Ln}$ & slow \\
\hline 70 & & CN: Building Sold: ytd & SA & $\triangle \mathrm{Ln}$ & slow \\
\hline 71 & & CN: Building Sold: ytd: Existing House & SA & $\triangle \mathrm{Ln}$ & slow \\
\hline 72 & & CN: Building Sold: ytd: House in Advance & SA & $\triangle$ & slow \\
\hline 73 & & CN: Building Sold: ytd: Residential & SA & $\triangle \mathrm{Ln}$ & slow \\
\hline 74 & & CN: Building Sold: ytd: Residential: Existing House & SA & $\triangle \mathrm{Ln}$ & slow \\
\hline 75 & & CN: Building Sold: ytd: Residential: House in Advance & SA & $\triangle$ & slow \\
\hline 76 & & CN: Building Sold: ytd: Commercial & SA & $\triangle \mathrm{Ln}$ & slow \\
\hline 77 & & CN: Building Sold: ytd: Commercial: Existing House & SA & $\triangle \mathrm{Ln}$ & slow \\
\hline 78 & & CN: Building Sold: ytd: Commercial: House in Advance & SA & $\triangle \mathrm{Ln}$ & slow \\
\hline 79 & \multirow{14}{*}{$\begin{array}{l}\text { Capital } \\
\text { Market }\end{array}$} & CN: Bond Index: Interbank: Treasury Bond: Short Term & NS & $\triangle \mathrm{Ln}$ & fast \\
\hline 80 & & CN: Bond Index: Interbank: Treasury Bond: Medium Term & NS & $\triangle \mathrm{Ln}$ & fast \\
\hline 81 & & CN: Bond Index: Interbank: Treasury Bond: Long Term & NS & $\triangle \mathrm{Ln}$ & fast \\
\hline 82 & & CN: Bond Index: Interbank: Policy Financial Bond & NS & $\triangle \mathrm{Ln}$ & fast \\
\hline 83 & & CN: Index: Shanghai Stock Exchange: Composite & NS & $\triangle \mathrm{Ln}$ & fast \\
\hline 84 & & CN: Index: Shenzhen Stock Exchange: Composite & NS & $\triangle \mathrm{Ln}$ & fast \\
\hline 85 & & CN: PE Ratio: Shanghai SE: All Share & SA & $\triangle \mathrm{Ln}$ & fast \\
\hline 86 & & CN: PE Ratio: Shanghai SE: A Share & SA & $\triangle \mathrm{Ln}$ & fast \\
\hline 87 & & CN: PE Ratio: Shanghai SE: Financial & SA & $\triangle \mathrm{Ln}$ & fast \\
\hline 88 & & CN: PE Ratio: Shanghai SE: Real Estate & SA & $\triangle \mathrm{Ln}$ & fast \\
\hline 89 & & CN: PE Ratio: Shanghai SE: Construction & NS & $\triangle \mathrm{Ln}$ & fast \\
\hline 90 & & CN: PE Ratio: Shanghai SE: Manufacturing & SA & Ln & fast \\
\hline 91 & & CN: PE Ratio: Shenzhen SE: All Share & NS & Ln & fast \\
\hline 92 & & Financial Institutions: balance of loans* & SA & $\triangle \mathrm{Ln}$ & fast \\
\hline 93 & \multirow{3}{*}{ Interest Rate } & CN: Nominal Lending Rate: 1-5 Year (Including 5 Year) & NS & $\triangle \mathrm{Ln}$ & slow \\
\hline 94 & & CN: Nominal Lending Rate: Over 5 Year & NS & $\triangle \mathrm{Ln}$ & slow \\
\hline 95 & & CN: Nominal Lending Rate: Individual Housing Provident Fund Loan: & NS & $\triangle \mathrm{Ln}$ & slow \\
\hline
\end{tabular}




\begin{tabular}{|c|c|c|c|c|c|}
\hline & & 5 Year or Less & & & \\
\hline 96 & & $\begin{array}{l}\text { CN: Nominal Lending Rate: Individual Housing Provident Fund Loan: } \\
\text { Over } 5 \text { Year }\end{array}$ & NS & $\triangle \mathrm{Ln}$ & slow \\
\hline 97 & & CN: Household Savings Deposits Rate: Time: 3 Month & NS & $\triangle$ & slow \\
\hline 98 & & CN: Household Savings Deposits Rate: Time: 6 Month & $\mathrm{NS}$ & $\triangle$ & slow \\
\hline 99 & & CN: Household Savings Deposits Rate: Time: 1 Year & $\mathrm{NS}$ & $\triangle$ & slow \\
\hline 100 & & CN: Household Savings Deposits Rate: Time: 2 Year & NS & $\triangle$ & slow \\
\hline 101 & & CN: Household Savings Deposits Rate: Time: 3 Year & NS & $\triangle$ & slow \\
\hline 102 & & CN: Shanghai Interbank Offered Rate (SHIBOR): Overnight & $\mathrm{NS}$ & NONE & fast \\
\hline 103 & & CN: Shanghai Interbank Offered Rate (SHIBOR): 1 Month & NS & NONE & fast \\
\hline 104 & & CN: Shanghai Interbank Offered Rate (SHIBOR): 3 Month & NS & $\triangle$ & fast \\
\hline 105 & & CN: Shanghai Interbank Offered Rate (SHIBOR): 6 Month & NS & $\triangle$ & fast \\
\hline 106 & & CN: Shanghai Interbank Offered Rate (SHIBOR): 1 Year & $\mathrm{NS}$ & NONE & fast \\
\hline 107 & \multirow{12}{*}{$\begin{array}{c}\text { Central Bank } \\
\text { Policies }\end{array}$} & CN: Money Supply M0 & SA & $\triangle \mathrm{Ln}$ & fast \\
\hline 108 & & CN: Money Supply M1 & SA & $\triangle \mathrm{Ln}$ & fast \\
\hline 109 & & CN: Money Supply M1: Demand Deposit & SA & $\triangle \mathrm{Ln}$ & fast \\
\hline 110 & & CN: Money Supply M2 & SA & $\triangle \mathrm{Ln}$ & fast \\
\hline 111 & & CN: Money Supply M2: Quasi Money & SA & $\triangle \mathrm{Ln}$ & fast \\
\hline 112 & & CN: Money Supply M2: Quasi Money: Saving Deposit & SA & $\triangle \mathrm{Ln}$ & fast \\
\hline 113 & & CN: Money Supply M2: Quasi Money: Time Deposit & SA & $\triangle \mathrm{Ln}$ & fast \\
\hline 114 & & CN: Money Supply M2: Quasi Money: Other Deposit & $\mathrm{NS}$ & $\triangle \mathrm{Ln}$ & fast \\
\hline 115 & & CN: Rediscount Rate & $\mathrm{NS}$ & $\triangle$ & slow \\
\hline 116 & & $\begin{array}{l}\text { CN: Central Bank Benchmark Interest Rate: Loan to FI: } 3 \text { Month or } \\
\text { Less }\end{array}$ & NS & $\triangle$ & slow \\
\hline 117 & & $\begin{array}{l}\text { CN: Central Bank Benchmark Interest Rate: Loan to FI: } 6 \text { Month or } \\
\text { Less }\end{array}$ & NS & $\triangle$ & slow \\
\hline 118 & & CN: Central Bank Benchmark Interest Rate: Loan to FI: 1 Year & $\mathrm{NS}$ & $\triangle$ & slow \\
\hline 119 & \multirow{6}{*}{$\begin{array}{c}\text { Fiscal } \\
\text { Revenue and } \\
\text { Expenditure }\end{array}$} & CN: Govt Revenue & SA & $\triangle \mathrm{Ln}$ & slow \\
\hline 120 & & CN: Govt Expenditure & SA & $\triangle \mathrm{Ln}$ & slow \\
\hline 121 & & CN: Govt Revenue: Tax & SA & $\triangle \mathrm{Ln}$ & slow \\
\hline 122 & & CN: Govt Revenue: Tax: Tariffs & SA & $\triangle \mathrm{Ln}$ & slow \\
\hline 123 & & CN: Govt Revenue: Tax: Value Added & SA & $\triangle \mathrm{Ln}$ & slow \\
\hline 124 & & CN: Govt Revenue: Tax: Stamp Duty: Securities Trading & NS & $\triangle \mathrm{Ln}$ & slow \\
\hline 125 & \multirow{2}{*}{$\begin{array}{c}\text { Macro } \\
\text { Expectation }\end{array}$} & CN: Consumer Confidence Index & $\mathrm{NS}$ & $\triangle \mathrm{Ln}$ & fast \\
\hline 126 & & CN: Consumer Expectation Index & $\mathrm{NS}$ & $\triangle \mathrm{Ln}$ & fast \\
\hline 127 & \multirow{5}{*}{$\begin{array}{l}\text { Macro- } \\
\text { Economy } \\
\text { of U.S. }\end{array}$} & Policy Rate: Month End: Effective Federal Funds Rate & \multirow{2}{*}{ NS } & \multirow{2}{*}{$\triangle$} & fast \\
\hline 128 & & Wu-Xia shadow rate* & & & fast \\
\hline 129 & & Industrial Production Index & SA & $\triangle \mathrm{Ln}$ & slow \\
\hline 130 & & Consumer Price Index: Urban & SA & $\triangle \mathrm{Ln}$ & slow \\
\hline 131 & & Unemployment Rate & SA & $\triangle$ & slow \\
\hline
\end{tabular}

